\title{
Numerical modelling of the flow in the annular multi-recess hydrostatic thrust bearing using CFD methods
}

\author{
M. Kozdera ${ }^{1}$, S. Drábková ${ }^{1}$ \\ ${ }^{1}$ Department of Hydromechanics and Hydraulic Equipment, Faculty of Mechanical Engineering, VŠB-Technical University \\ of Ostrava, 17. listopadu 15/2172, Ostrava, Czech Republic
}

\begin{abstract}
The current research of hydrostatic bearings and hydrostatic slide-ways is far from being over. The topic is constantly evolving, creating new geometries of the sliding bearings, developing new types of friction materials and lubricants. The control elements of hydraulic mechanisms that serve to regulation of the hydrostatic bearings tipping are still in progress. Almost every application has different requirements for the bearings, whether in terms of loading capacity, speed rotation, and also the price. All these aspects should be included in the design of hydrostatic thrust bearings. Thanks to great advances in the development of computer technology and software for numerical modelling, we can simulate real movement of viscous fluids. To create a numerical model of hydrostatic thrust bearing, Ansys Fluent 14.0 software package has been applied. The article describes the basic methods of numerical modelling of the given problem and evaluates the pressure field and the loading capacity of annular multi-recess hydrostatic thrust bearing and its dependence on the change in static pressure.
\end{abstract}

\section{Introduction}

The inventor of the hydrostatic bearing was L. D. Girard. In 1851 he patented the water hydrostatic bearing for the railway propulsion. It is reported that friction and wear were almost eliminated; the coefficient of friction was reduced to 0.002 . In 1864 he expanded his theory of slideways where the load was transferred to the surface of hydrostatically lubricated plates. Since then there have been many patents on the topic. However, most of these innovations and designs have never been used in any practical device. One of the reasons was that it was possible to determine their performance for a given application [1], [2].

Rayleigh (1917) described the hydrostatic thrust bearing and introduced equations to calculate the load, flow rate and the friction moment [1].

Rippel in 1964 defined the basic concepts of hydrostatic bearings. He introduced a simple type geometry lubricating recesses. He defined capillary reducer, orifice reducer and reducer with constant flow for control pressure [3].

Neal published in 1973 Tribology Handbook, where among other things he dealt with hydrostatic bearings. He proposed a method of stiffness determination for hydrostatic thrust bearing with one central groove, where he also proved the influence the chosen reducer on the hydrostatic bearings stiffness [4].

Ghosh and Mujumdar (1982) dealt with the analysis of the dynamic behaviour of hydrostatic bearings. They considered inertia of a fluid and influence of air compressibility. The results were presented for capillary and orifice reducers [5].

Rowe in 1983 wrote the basic theory for the design of control valves of the hydrostatic bearing. He used theorems, which are mainly related to the static properties of different types of hydrostatic bearings and reducers (capillary, slot, orifice, with constant flow rate) [6].

Bassani and Piccigallo (1992) defined the static load, flow rate and static stiffness of majority reducers in common types of hydrostatic equipment. Then in 2001 Bassani modified the theory for hydrostatic bearing with opposite recesses $[2,7]$.

Yoshimoto et al in 1993 published an article about a rectangular hydrostatic bearing. The result indicates that very high stiffness of bearing can be achieved through a butterfly valve [8].

Osman et al (1996) compared hydrostatic thrust bearing with one central recess and more lubrication recesses in their article. They recommend the use of hydrostatic bearing with multiple recesses for greater load. In addition, this bearing needs less grease. With increasing load the thickness of sliding layer decreases. 
This phenomenon is more significant in case of smaller radius of the recesses location from the axis of rotation [9].

Generally, the hydrostatic thrust bearings are designed to work with parallel surfaces. However, heat distortion, manufacturing, construction and installation errors can cause the tilting of the plate. Many scientists [10-15] were interested in examining the tilting of the plate and its impact on the performance characteristics of hydrostatic thrust bearing. If the sliding bearing is loaded, the plastic deformation of the plate changes the profile of the fluid film and thus the performance characteristics. These studies show that flexibility of the bearing quite significantly influences its performance characteristics and for optimum design parameters such as the type of reducer must be taken into account.

Weck, Henning and Winterschladen (2011) published an article on the influence of recesses shape in the hydrostatic thrust bearing with central recess. Research indicates that for certain applications, the reducer can be replaced with the recess of appropriate shape [16].

Researchers began to apply numerical methods to simulate the flow in the hydrostatic bearing around 2000 , for example $[16,17]$.

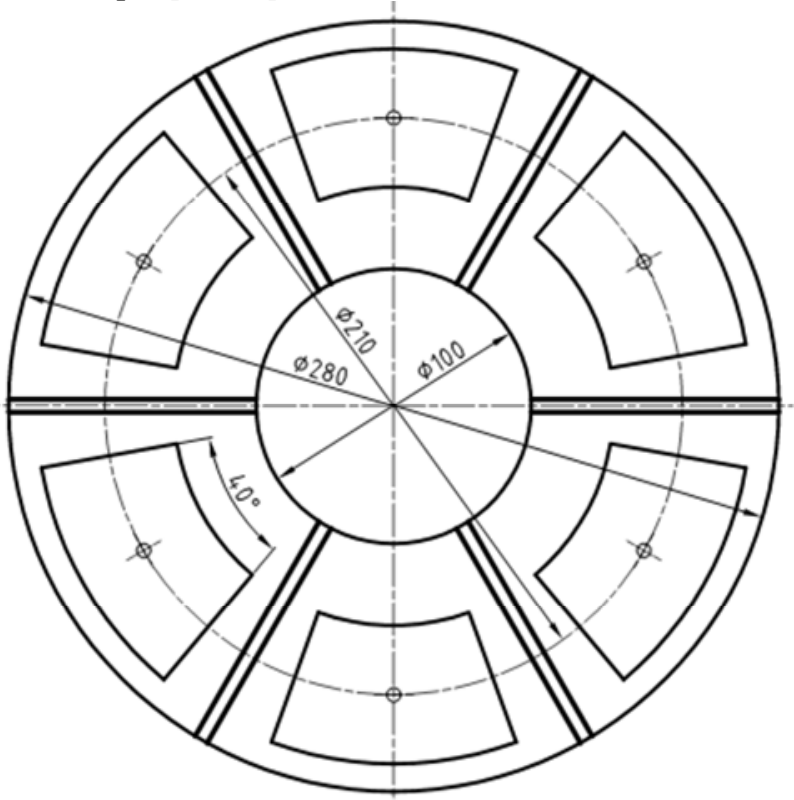

Detail of the recess
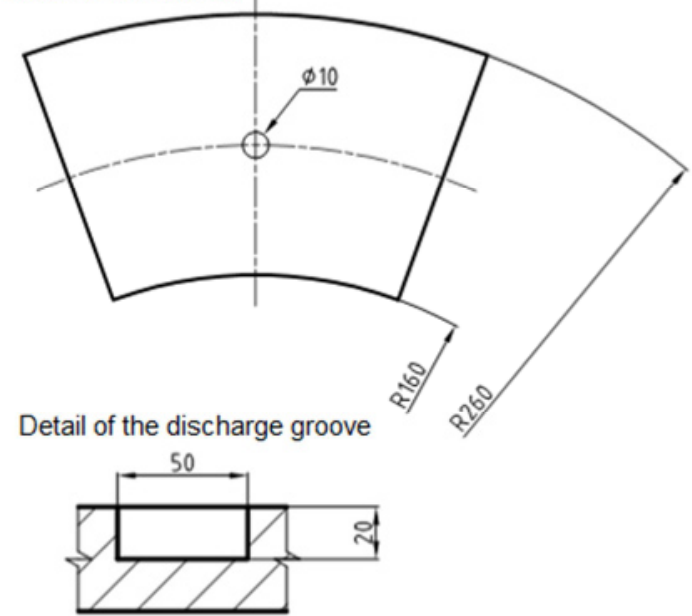

Fig. 1. Geometry of the hydrostatic thrust bearing
Numerical modelling has been applied to investigate the flow in the hydrostatic thrust bearing (figure 1). For the designed geometry of the bearing mathematical model was created, simulations were carried out with the Ansys Fluent 14.0. In the paper two types of the numerical model are compared, namely:

* laminar model,

* LES model.

Model LES (Large Eddy Simulation) belongs to turbulent models and is based on the simulation of large vortices as time-dependent spatial units that can be caught with mesh.

\section{Geometry and computational mesh of the hydrostatic thrust bearing}

The spatial model of the hydrostatic thrust bearing (figure 1) was created in the Ansys Design Modeler which is part of Workbench. The volume of liquid is defined with the movable and fixed surface of the bearing plates. The design contains six recesses, which are placed between the discharge grooves of rectangular cross section. The maximum diameter of the bearing is $280 \mathrm{~mm}$ and the minimum diameter is $100 \mathrm{~mm}$. The liquid is fed to the recesses through the hole with diameter $10 \mathrm{~mm}$. The geometry of the recesses does not include roundness and canting of edges, which is negligible in this case.

After creating the geometry, the computational mesh was generated using the Ansys Meshing that divides the liquid into elementary volumes (figure 2 and figure 3 ). A mesh is a system of division of the calculation volume into the $3 \mathrm{D}$ cells. The mesh is the basis for the application of mathematical modelling. The actual mathematical model (system of mathematical relations) is only "passive" tool, which comes into effect only when it is applied to a specific problem $[18,19]$.

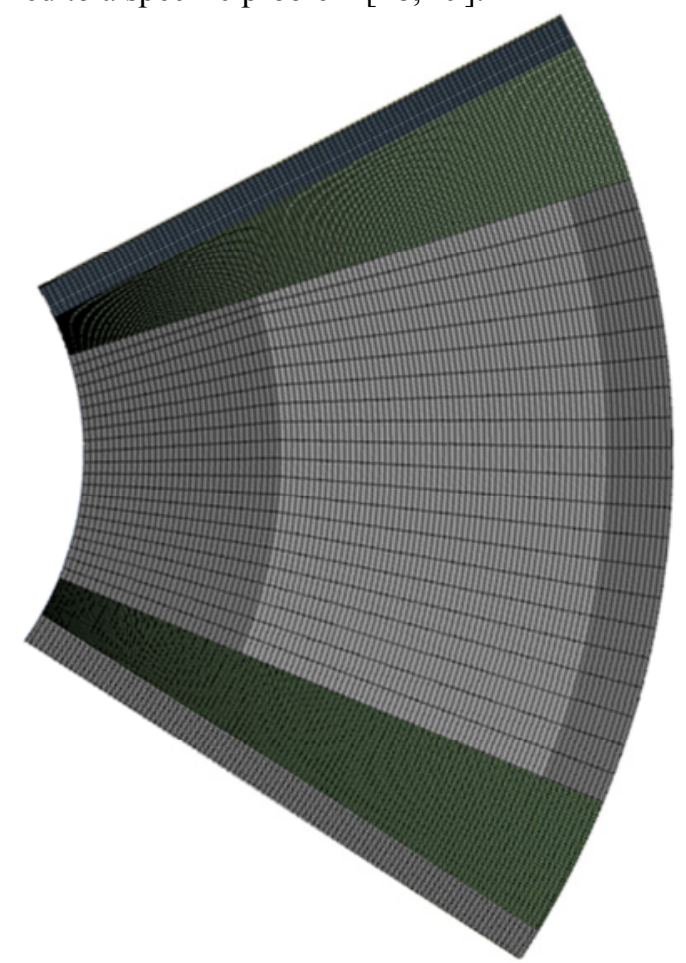

Fig. 2. Detail of the computational mesh - front view 


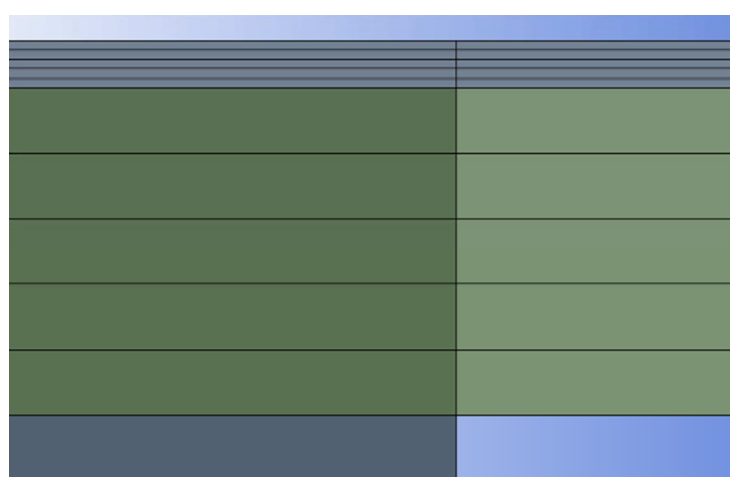

Fig. 3. Detail of the computational mesh - side view

\section{Definition of the mathematical model and boundary conditions of the hydrostatic thrust bearing}

Fluid flow in the narrow gap of the hydrostatic thrust bearing is connected with the solution of the problem, which is defined as:

* three dimensional flow,

* laminar flow,

* incompressible flow ( $\rho=$ const.),

* isothermal flow (without considering heat transfer, $T=$ const.),

* unsteady flow.

Generally, laminar flow is expected in very narrow gaps, where the liquid flows.

An important part of the hydrostatic thrust bearing design is the choice of a suitable lubricant. Mineral oil was chosen for slide ways, which is characteristic by high adhesion and low friction values. Its dynamic viscosity at $40{ }^{\circ} \mathrm{C}$ is $0.13335 \mathrm{~Pa} \cdot \mathrm{s}(150 \mathrm{cSt})$ and the density of 889 $\mathrm{kg} / \mathrm{m}^{3}$ [20].

In the CFD program Fluent the following types of boundary conditions can be defined:

* conditions for input and output of the flow,

* conditions on the wall,

* symmetry conditions,

* periodic (cyclic) conditions,

* time dependent boundary conditions.

Other boundary conditions do not directly relate to the flow itself, but they concern other quantities implied from complexity of the mathematical model, e.g. temperature $[18,19]$.

In the hydrostatic thrust bearing, the input boundary condition was defined by "Mass Flow Inlet", where we defined the mass flow rate per lubrication recess. Two different variants were compared:

a) $0.01482 \mathrm{~kg} / \mathrm{s}$, which corresponds to the volumetric flow rate per on recess $11 / \mathrm{min}$,

b) $0.02963 \mathrm{~kg} / \mathrm{s}$, which corresponds to the volumetric flow rate per on recess $2 \mathrm{l} / \mathrm{min}$.

At the outlet of the bearing "Pressure Outlet" condition was defined, which was set to gauge pressure equal zero.

Since the whole geometry of the bearing was created, we could define different value of the mass flow rate separately for each recess. This was an advantage in case of regulation of flow in the slide bearing and the tilt of the moving wall. If the bearing geometry was defined only as a section and the whole geometry was created by means of periodic conditions, we could not define the size of the mass flow rate in every single recess.

The top plate carries a rotary motion, constant speed $n$ $=0.1 \mathrm{l} / \mathrm{s}$ was defined. In case of time dependent solution the wall motion generates deformation of the mesh. Therefore, in our case sliding mesh technique was applied. Fluidized layer was divided into two annuluses (figure 4). The maximal height of the grease layer was $0.1 \mathrm{~mm}$. The upper moving fluidized layer had the height $0.01 \mathrm{~mm}$. The height of the lower stationary mesh varied from 0.09 to $0.03 \mathrm{~mm}$. For the modelling of this type of problems two approaches could be applied:

* MRF method (multiple reference frame),

* MM method (moving mesh).

The MM model was used in our case. The area of flow was divided into several zones separated by "interface" which connects the elementary volumes. The advantage of the method is that there is no deformation of the mesh, but each zone slip together. The solution is unsteady.

\section{rotating wall moving mesh interface \\ solid mesh \\ solid wall \\ Fig. 4. Principle of sliding mesh \\ 4 Application of mathematical model on the hydrostatic thrust bearing}

Time dependent solution was evaluated after one revolution of rotating plate. It turned out that after the creation of the fluidized layer and static pressure in the bearing, its load stabilized at a constant value. For this reason, additional calculations were performed only for one revolution of the plate. Results are shown in Table 1 and 2. Load capacity and static pressure are compared for each fluid layer thickness and two different volumetric flow rates.

Table 1. Evaluation of numerical model

\begin{tabular}{|c|c|c|}
\hline \multicolumn{3}{|c|}{ Volumetric flow rate for one recess } \\
\hline \begin{tabular}{c}
$Q_{v l}=1 \mathrm{l} / \mathrm{min}$ \\
\hline $\begin{array}{c}\text { Height of fluidized } \\
\text { layer }\end{array}$
\end{tabular} & $\begin{array}{c}\text { Load of } \\
\text { the bearing }\end{array}$ & $\begin{array}{c}\text { Maximum } \\
\text { static pressure }\end{array}$ \\
\hline$[\boldsymbol{h}]=\mathrm{mm}$ & {$[\boldsymbol{F}]=\mathrm{N}$} & {$[\boldsymbol{p}]=\mathrm{MPa}$} \\
\hline 0.1 & 43679.2 & 1.33 \\
\hline 0.08 & 82668 & 2.5 \\
\hline 0.06 & 135370 & 5.14 \\
\hline 0.03 & 236889 & 8.86 \\
\hline
\end{tabular}


Table 2. Evaluation of numerical model

\begin{tabular}{|c|c|c|}
\hline \multicolumn{3}{|c|}{ Volumetric flow rate for one recess } \\
\hline \begin{tabular}{c}
$Q_{v l}=21 / \mathrm{min}$ \\
\hline $\begin{array}{c}\text { Height of fluidized } \\
\text { layer }\end{array}$
\end{tabular} & $\begin{array}{c}\text { Load of } \\
\text { the bearing }\end{array}$ & $\begin{array}{c}\text { Maximum } \\
\text { static pressure }\end{array}$ \\
\hline$[\boldsymbol{h}]=\mathrm{mm}$ & {$[\boldsymbol{F}]=\mathrm{N}$} & {$[\boldsymbol{p}]=\mathrm{MPa}$} \\
\hline 0.1 & 88293 & 2.61 \\
\hline 0.08 & 172650 & 5.37 \\
\hline 0.06 & 288144 & 10.2 \\
\hline 0.03 & 477426 & 18.4 \\
\hline
\end{tabular}

The results show that with increasing of the fluidized layer height the static pressure decreases same as the load capacity of the hydrostatic thrust bearing (figure 5 and figure 6). The objective of the design is therefore to achieve an optimum height of the fluidized layer, when the load capacity reaches its maximum. However, the value of pressure in the circuit must be taken into account, not to exceed the permissible limit. Also the contact of the sliding surfaces must be avoided; with reduction of the height of the lubricant layer it is difficult to achieve the required accuracy of machining, especially in large size bearings.

$$
p=f(h)
$$

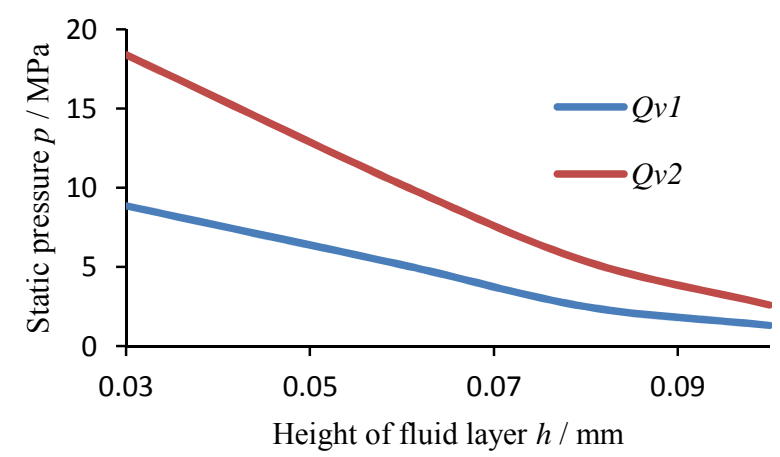

Fig. 5. The dependence of the static pressure on the fluidized layer height

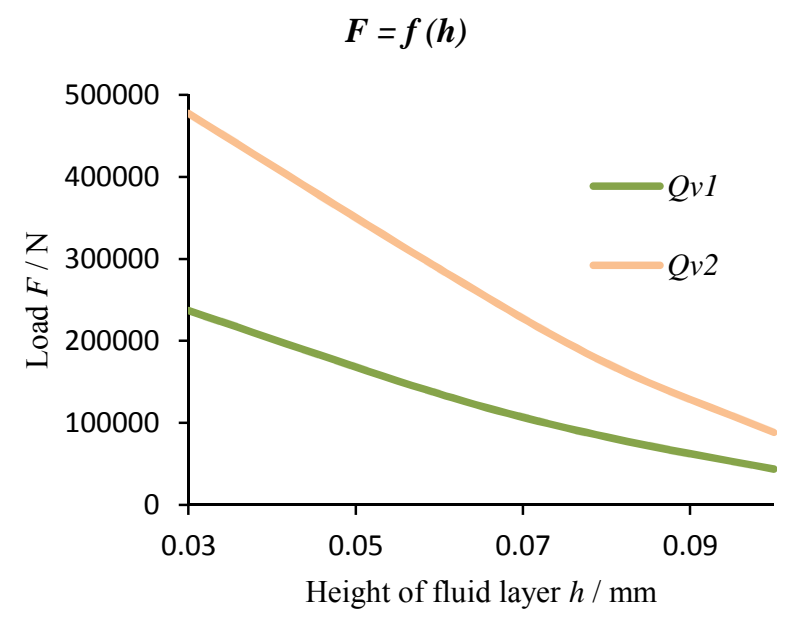

Fig. 6. The dependence of the load on the fluidized layer height
In figures $7-10$ results are compared obtained with different numerical models (laminar model and LES model). Figures 7 and 8 show the static pressure distribution in the narrow gap of the hydrostatic thrust bearing in case of volumetric flow rate $11 / \mathrm{min}$ and fluidized layer height $0.1 \mathrm{~mm}$. Evaluation plane is placed at half height of the lubricating film.

For other variants of the fluidized layer height hydrostatic thrust bearing behaves in the same way, so the pressure field distribution is similar, only the size of static pressure changes. It is apparent that the maximum static pressure (show in red) in the bearing is at the inlet and decreases gradually toward the outlet. Lubrication recesses are separated by discharging grooves, where the static pressure is zero, i.e. they are working properly, as they are not influenced by neighboring recesses.

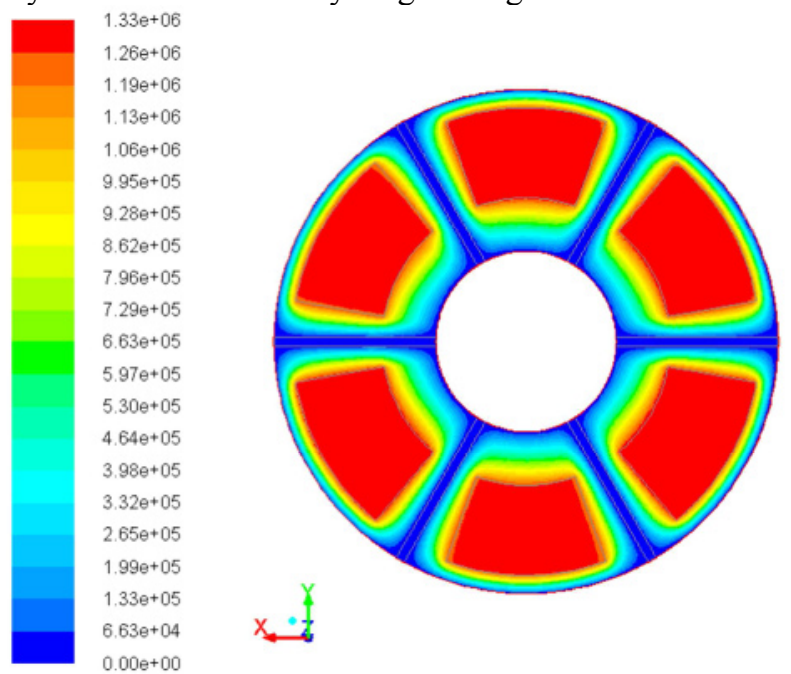

Fig. 7. Pressure field in the hydrostatic thrust bearing, height of fluidized layer $0.1 \mathrm{~mm}$, unit $(\mathrm{Pa})$ - laminar model

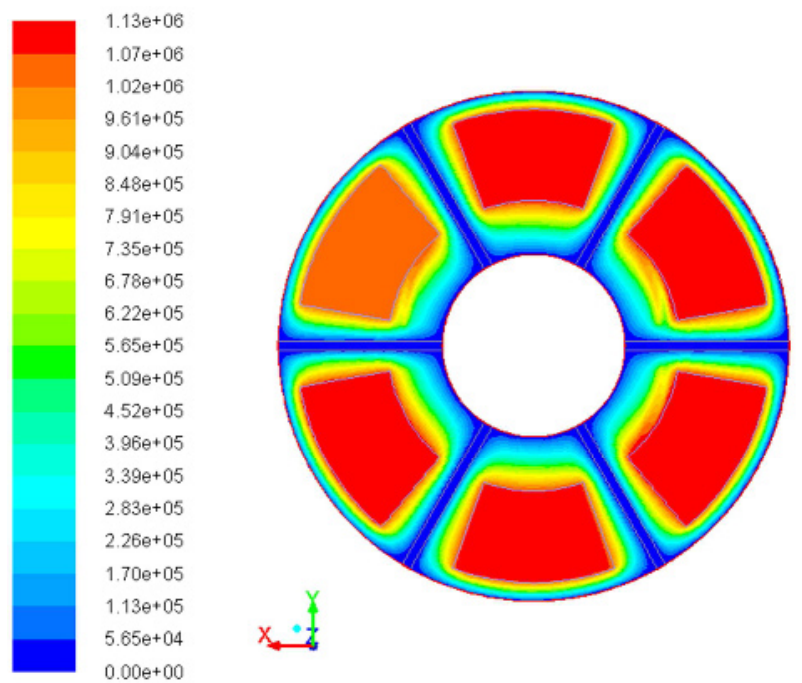

Fig. 8. Pressure field in the hydrostatic thrust bearing, height of fluidized layer $0.1 \mathrm{~mm}$, unit $(\mathrm{Pa})$ - LES model 


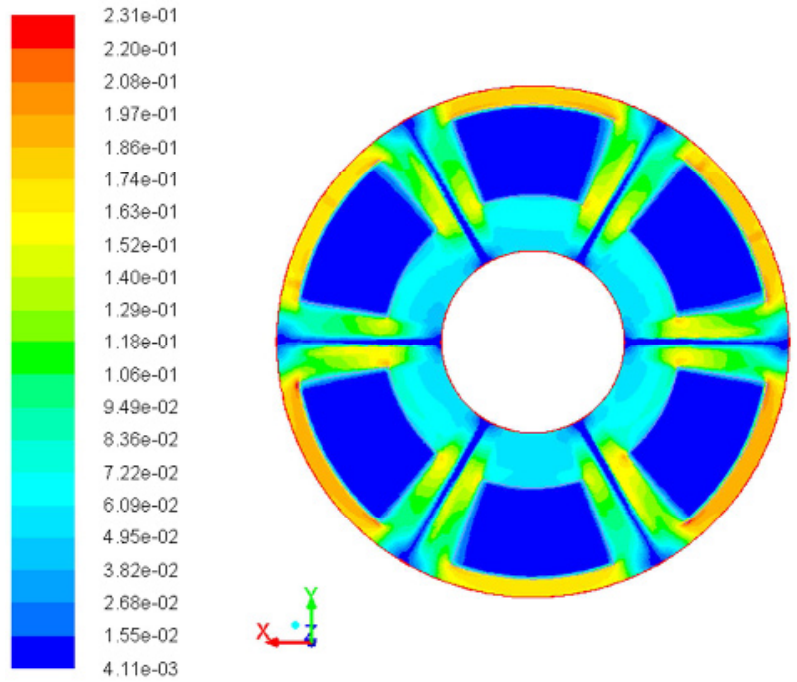

Fig. 9. Velocity field in the hydrostatic thrust bearing, height of fluidized layer $0.1 \mathrm{~mm}$, unit $(\mathrm{m} / \mathrm{s})$ - laminar model
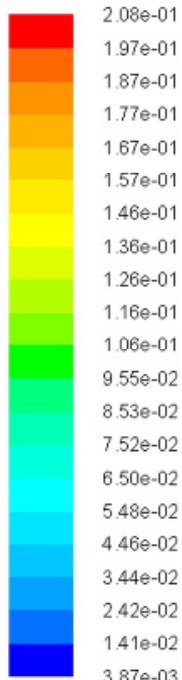

$387 e-03$

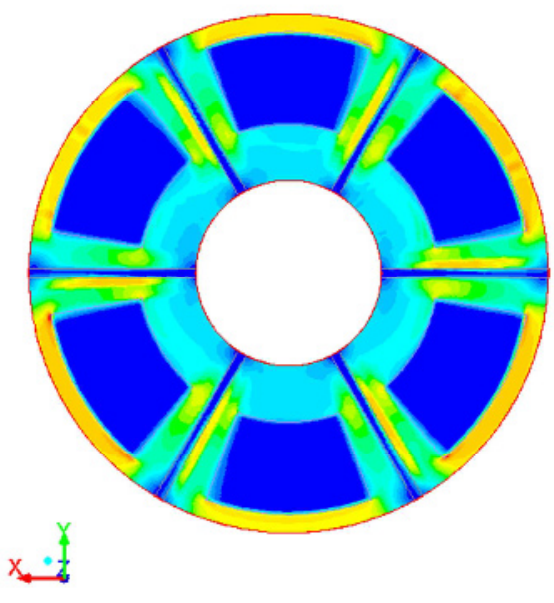

Fig. 10. Velocity field in the hydrostatic thrust bearing, height of fluidized layer $0.1 \mathrm{~mm}$, unit $(\mathrm{m} / \mathrm{s})$ - LES model
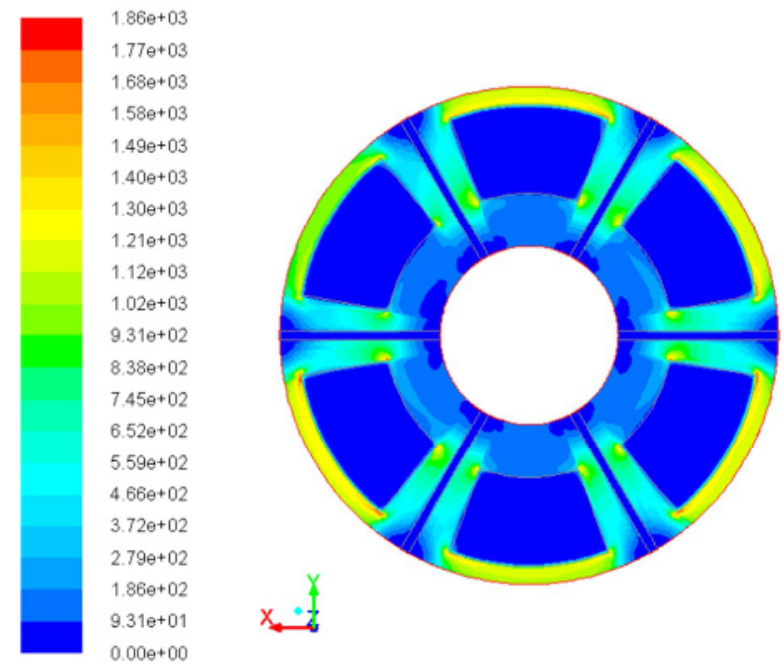

Fig. 11. Evaluation of hydrodynamic pressure in the hydrostatic thrust bearing, height of fluidized layer $0.1 \mathrm{~mm}$, unit $(\mathrm{Pa})$ laminar model
Velocity field in the hydrostatic thrust bearing is shown on figures 9 and 10 . Here can be seen that the liquid chooses the path of least resistance and flows the shortest way out of the bearing.

Figure 11 shows the hydrodynamic pressure in the slide bearing. The maximum value is $1860 \mathrm{~Pa}$. In comparison with the static pressure it is negligible. However, the tilt of the upper plate creates a wedgeshaped gap, and this increases the hydrodynamic pressure in the hydrostatic thrust bearing.

\section{Conclusions}

In the paper we examined the flow of real fluid in the hydrostatic thrust bearing. This is a very broad interdisciplinary topic that involves the viscous fluid flow, tribology, thermomechanics and others. Hydrostatic thrust bearing belongs to the sliding bearings, whose load force is acting in the direction of the bearing axis. Sliding surfaces are separated by a layer of grease. Mineral oil transmits pressure energy and is acting on the moving plate of the bearing. For the design and optimization of hydrostatic thrust bearings it is necessary to investigate the bearing geometry (shape of the recess, shape of the discharge groove, size of the effective area) and its influence on the performance characteristics.

Hydrostatic bearing of annular shape was proposed. Ansys software was applied to create 3D geometry of the model and computational mesh consisting of hexahedrons. For comparison of the results, two numerical models were tested (laminar model and LES model).

The liquid is fed to six lubrication recesses. So that the individual recesses do not interfere with each other, discharge grooves were inserted between them. Evaluation of velocity field in figure 9 (or figure 10) shows that the fluid flows either toward the outlet of the bearing or is drained by discharge grooves back into the reservoir. From result we may assume that the discharge grooves meet the requirements of sufficient capacity.

An important factor in the practice is load capacity of the hydrostatic thrust bearing which is essentially given by the size of the static pressure in the bearing. The results are compared in table 1 and table 2 and graphically evaluated in figure 5 and figure 6 . The results show that with growing height of the fluidized layer the static pressure and load capacity decreases. Thickness of the fluidized layer is one of the major factors affecting the performance characteristics of the hydrostatic bearing. There is an effort to achieve minimum height, but it is limited by the quality of sliding surfaces. The production of smaller bearing diameters is relatively simple and high accuracy can be reached. The problem occurs with large bearings which have a diameter in the order of meters.

To confirm the accuracy of the solution, calculation were carried out with laminar and LES model. The pressure field (figure 7 and figure 8) and velocity filed (figure 9 and figure 10) predicted with both model do not differ, the results are essentially concurring. In the mathematical model it was not accounted for the air in the mineral oil. This influences the compressibility of the fluid. Also the heating of mineral oil during its passage 
through the bearing was not included. These aspects can have an impact on the bearing performance. How large these aspects influence the behaviour of the hydrostatic thrust bearing will be investigated in further research.

\section{References}

1. A. Cameron, Basic lubrication theory (1971)

2. Y. Kang, J. L. Lee, Design for static stiffness of hydrostatic plain bearings: constant compensation. Industrial Lubrication and Tribology 63/3 (2011)

3. H. C. Rippel, Cast Bronze Hydrostatic Bearing Design Manual (1964)

4. M. Neal, Tribology Handbook (1973)

5. M. K. Ghosh, B. C. Mujumdar, Dynamic stiffness and damping characteristics of compensated hydrostatic thrust bearings. ASME J. of Lubrication Technology 104 (1982)

6. W. B. Rowe, Hydrostatic and Hybrid Bearing Design (1983)

7. R. Bassani, B. Piccigallo, Hydrostatic Lubrication (1992)

8. S. Yoshimoto, Y. Anno, M. Fujimora, Static characteristics of a rectangular hydrostatic thrust bearing with a self-controlled restrictor employing a floating disk. ASME J. of Tribology 115 (1993)

9. T. A. Osman, M. Dorid, Z. S. Safar, M. O. A. Mokhtar, Experimental assessment of hydrostatic thrust bearing performance. Tribology International 29(3) (1996)

10. M. F. Khalil, K. A. El-Shorbagy, Surface roughness effects on externally pressurized bearing performance. Wear 103(1) (1985)

11. R. Sinhasan, S. C. Jain, Lubrication of orifice compensated flexible thrust pad bearing. Tribology 17(4) (1984)

12. R. Sinhasan, S. C. Jain, S. C. Sharma, Orifice compensated flexible thrust pad bearings of different configuration. Trib. International 19(5) (1986)

13. A. Van Beek, R. A. J. Van Ostayen, Analytical solution for tilted hydrostatic multi-pad thrust bearings of finite length. Tri. International 30(1) (1997)

14. A. Van Beek, A. Segal, Numerical solution for tilted hydrostatic multi-pad thrust bearings of finite length. Trib. International 30(1) (1997)

15. A. Van Beek, A. Segal, Rubber supported hydrostatic thrust bearings with rigid bearing surfaces. Trib. International 30(1) (1997)

16. M. Weck, J. Henning, M. Winterschladen, Development of hydrostatic bearings with grooves structures (2011)

17. S. C. Sharma, S. C. Jain, D. K. Bharuka, Influence of recess shape on the performance of a capillary compensated circular thrust pad hydrostatic bearing. Trib. International 35 (2002)

18. T. Blejchař, Mat. modelování nestacionárního proudéní, kavitace a akustických projevů v hydraulickém ventilu (2006)

19. M. Kozubková, Num. modelování proudění (2008)

20. P. Blaškovič, J. Balla, M. Dzimko, Tribológia (1990)
The results presented in this paper were achieved within the specific research project SP2012/55 "Modelování dynamiky tekutinových mechanismů" solved at Faculty of Mechanical Engineering, VŠB Technical University of Ostrava in 2012. 